\title{
Vertical movement during the quiescent phase of the Murono mud volcano, Niigata, Japan
}

\author{
Shigekazu Kusumoto ${ }^{*}$, Keiya Sudo², Mika Kawabata², Toshiaki Uda ${ }^{1}$ and Yoichi Fukuda ${ }^{3}$
}

\begin{abstract}
In order to quantify vertical movements during the quiescent phase of the Murono mud volcano area located in Niigata, Japan, we set up 61 benchmarks and conducted leveling measurements five times in 2012. We also performed a dense gravity survey on the benchmarks to obtain information on subsurface structures. Uplifting of approximately $26 \mathrm{~mm}$ and subsidence of $14 \mathrm{~mm}$ were detected from observations. The uplift area corresponded to a previously uplifted area and had low gravity, which is suggestive of the presence of fluid mud. We propose that overpressure changes in the fluid mud led to surface deformation.
\end{abstract}

Keywords: Mud volcano; Vertical movement; Leveling; Gravity survey; Overpressure; Fluid mud

\section{Findings}

Introduction

Mud volcanoes are frequently located on the crests of anticlines in fold and thrust belts (e.g., Chigira and Tanaka 1997; Fowler et al. 2000; Bonini 2007; Morley 2007), and they are regarded as features that indicate the presence of petroleum reservoirs (e.g., Feyzullayev and Lerche 2009). Mud volcanoes are also a natural source of atmospheric methane, which is a powerful greenhouse gas (e.g., Dimitrov 2003; Etiope and Milkov 2004; Etiope et al. 2008). In recent years, it has been suggested that mud volcanoes are useful indicators of stress orientation and tectonic controls (e.g., Bonini and Mazzarini 2010; Bonini 2012).

Mud volcanoes become active because of mechanical factors such as nearby large earthquakes and drilling (e.g., Chigira and Tanaka 1997; Panahi 2005; Mellors et al. 2007; Davies et al. 2008; Manga et al. 2009). For example, mud volcanoes in Niikappu (Hokkaido, Japan) have been observed to erupt in response to earthquakes (e.g., Chigira and Tanaka 1997). Moreover, the recent activities of the Lusi mud volcano in Indonesia have been attributed to the pressure of drilling fluids used to initiate hydrofracturing (e.g., Davies et al. 2008). However, an earthquake is still a conceivable mechanism that

\footnotetext{
* Correspondence: kusu@sci.u-toyama.ac.jp

${ }^{1}$ Graduate School of Science and Engineering for Research (Science),

University of Toyama, 3910 Gofuku, Toyama 930-8555, Japan

Full list of author information is available at the end of the article
}

could have triggered eruptions at Lusi (e.g., Mazzini et al. 2009), and the triggering mechanism for the recent eruptions at the Lusi mud volcano remains controversial.

The Murono mud volcano examined in this study is very small in size $(70 \mathrm{~m} \times 100 \mathrm{~m})$, and it is located in the vicinity of an unnamed anticline limb of the Naradate syncline (Figure 1) (e.g., Noda 1962). Our study area was located in the Tertiary sedimentary basin in Niigata Prefecture. This sedimentary basin, which is known as the Niigata basin, has many fold structures in the NE-SW direction and is one of the most important petroleumproducing areas in Japan. Thus, this mud volcano has been investigated by numerous researchers from geophysical and geochemical perspectives (e.g., Onishi et al. 2009; Shinya and Tanaka 2009; Suzuki et al. 2009; Etiope et al. 2011).

The Murono mud volcano has been deformed by neighboring large earthquakes, as mentioned above. Vertical movements observed by local Global Positioning System (GPS) surveys in the Murono mud volcano area before and after the Niigataken Chuetsu-oki earthquake in 2007 (Figure 1, Mw = 6.6; e.g., Imanishi and Kuwahara 2009) have reached approximately $400 \mathrm{~mm}$ (Onishi et al. 2009). Onishi et al. (2009) suggested that this conspicuous vertical movement was caused by the effects of this earthquake on the mud volcano, but other conspicuous crustal movements due to this earthquake were not observed by the regional GPS network operated in this area by the 


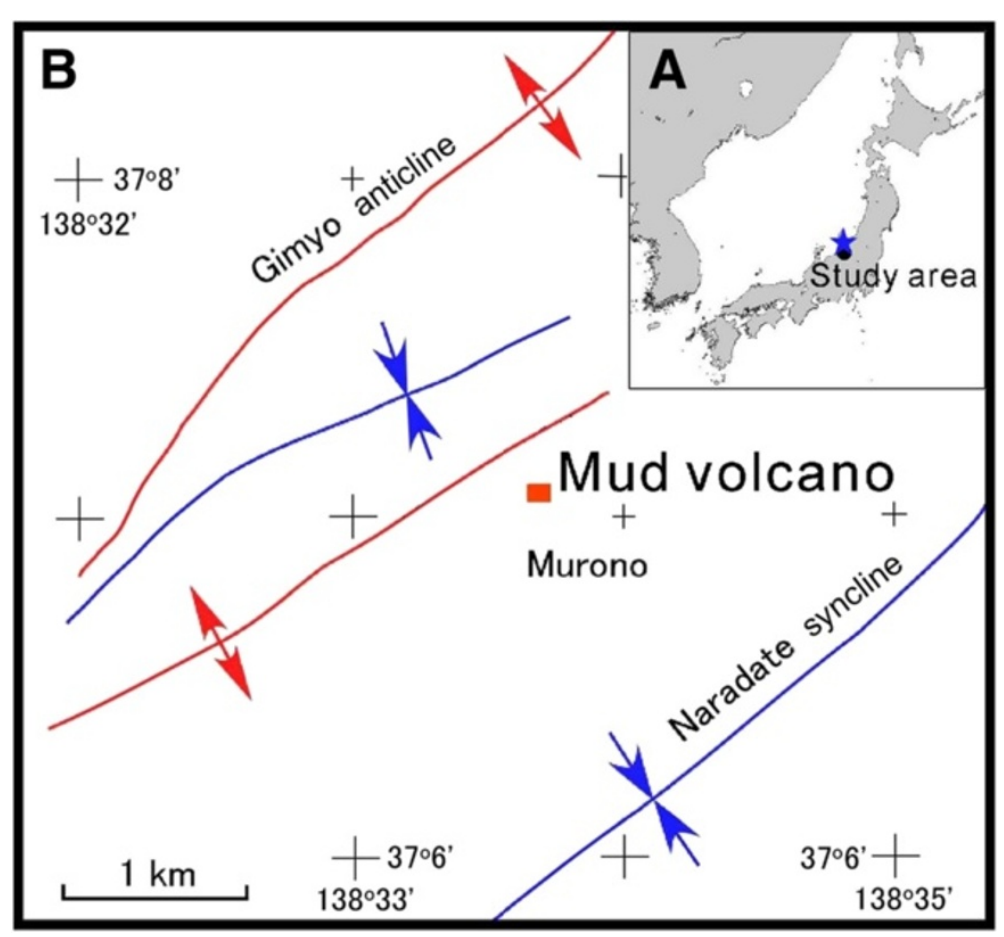

Figure 1 Location of the Murono mud volcano, Niigata, Japan. (A) Location of the study area in the Tertiary sedimentary basin in Niigata Prefecture and in the back-arc of central Japan. The blue star indicates the epicenter of the Niigataken Chuetsu-oki earthquake. (B) Location of the Murono mud volcano and distribution of folds (after Takeuchi et al. 2000). Red and blue lines indicate the anticline and syncline structures, respectively.

Geographical Survey Institute of Japan (GSI)). The distance between the epicenter and the mud volcano area was about $44 \mathrm{~km}$, and these data highlight that it is important to understand the behavior of the Murono mud volcano in response to neighboring large earthquakes. The same type of movement is expected in the near future because Niigata, including our study area, has a strain rate (approximately $0.1 \mathrm{ppm} /$ year) that is an order of magnitude larger than other areas of Japan (approximately $0.01 \mathrm{ppm} /$ year). Furthermore, this region is known to be part of a strain concentration belt (e.g., Sagiya et al. 2000). Consequently, it is important to observe inter-seismic vertical movement by periodic precise leveling in order to obtain the status of the mud volcano at rest and to examine the source of any conspicuous vertical movements.

In this study, we conducted precise leveling and gravity surveys around the Murono mud volcano to show the vertical movement during a 6-month period and measured the relationship between movement and the gravity anomaly.

\section{Observations and data processing}

We set up benchmarks at 61 points (Figure 2) where vertical movements have been previously observed (e.g., Onishi et al. 2009) and then performed precise leveling measurements five times over several months. Specifically, leveling was done one time each month in June, July, October, November, and December of 2012 with an automatic digital level. Observations in August and September could not be performed because of bad weather. We were also unable to conduct surveys in January to May because the area was covered with snow.

The benchmarks were connected via 12 leveling routes. The survey of each leveling route consisted of a round trip where we conducted the leveling so that the round trip difference was zero. Each elevation was determined by geodetic net adjustment (e.g., Bonford 2012) referenced to the elevation of $\mathrm{A} 0$, and the elevation of the datum point A0 was determined by the leveling from a second-order benchmark (BM2167-7) administered by GSIJ. The standard deviations of our leveling had a maximum of $1.96 \mathrm{~mm}$ and a minimum of $0.75 \mathrm{~mm}$ during June to December 2012.

Gravity surveys using a LaCoste \& Romberg G-680 gravimeter (Lacoste \& Romberg-Scintrex Inc., 222 Snidercroft Road Concord, L4K 2K1 Ontario, Canada) were performed on the benchmarks ( 45 points shown as bull's eyes in Figure 2) by the round-trip measurement method. Measurement accuracy was better than $20 \mu \mathrm{Gal}$. We performed a series of gravity corrections (e.g., HofmannWellenhof and Moritz 2006) to obtain the Bouguer gravity anomaly. For the terrain correction, we employed the 

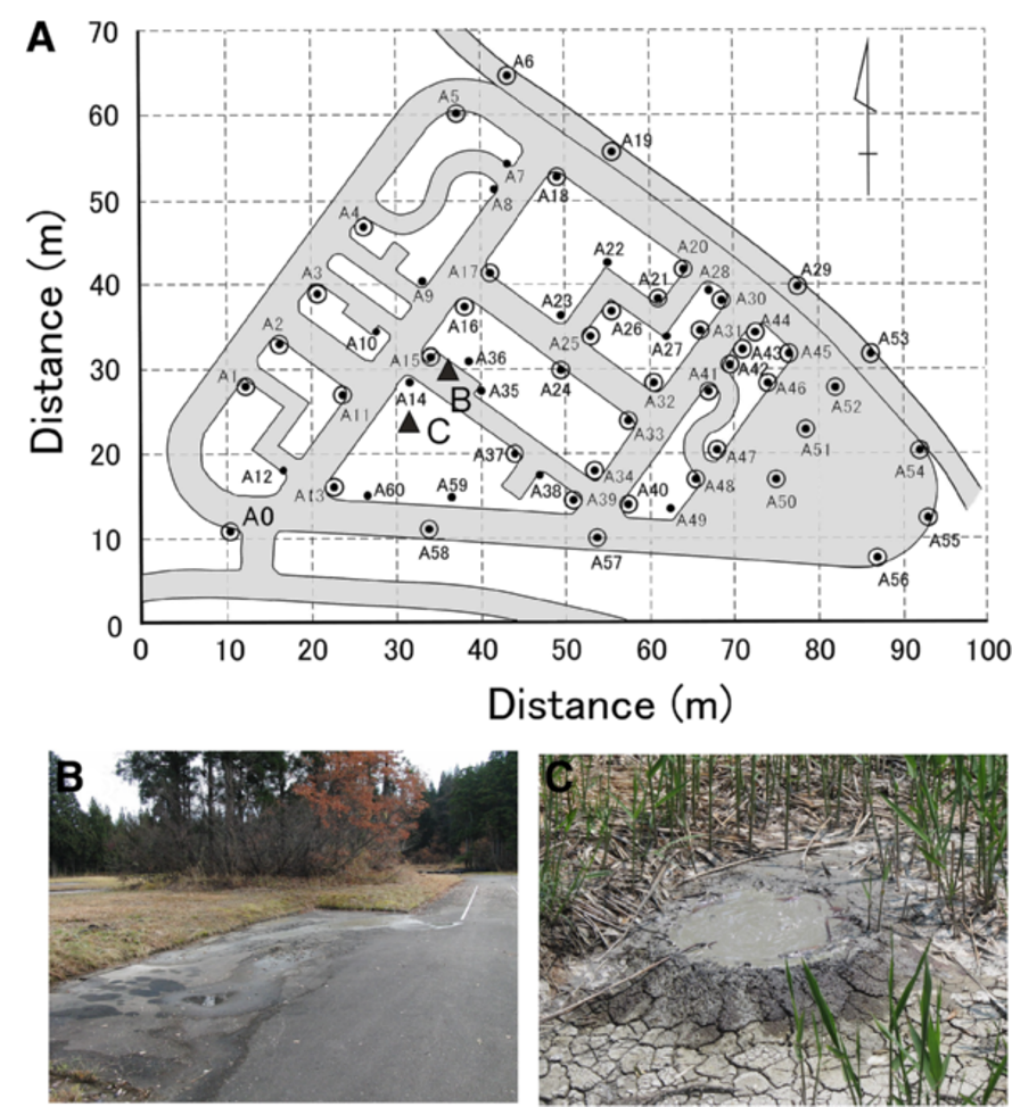

Figure 2 Distribution of observation points and appearance of vents. (A) Distribution of benchmarks (61 points: A0 to A60) and gravity measurement points (45 points: shown as bull's eyes). Roads are colored light gray. Triangles indicate the locations of vents B and C. (B) Appearance of vent B near point A36. This vent consists of more than one small vent. (C) Appearance of vent C near point A14. The diameter of this vent is approximately $30 \mathrm{~cm}$.

formula of Banerjee and Gupta (1977) and used digital elevation mesh data with $50-\mathrm{m}$ intervals by GSIJ. Gravitational effects within a radius of $20 \mathrm{~km}$ were corrected. The Bouguer density was assumed to be $2,400 \mathrm{~kg} / \mathrm{m}^{3}$.

\section{Results}

\section{Vertical movements}

Figure 3 shows the total vertical movement during June to December 2012, where we assumed A0 to be fixed. The displacements are shown in millimeters, and the contour intervals are $2.5 \mathrm{~mm}$.

The dominant movement in this area was uplift, and the uplift area was surrounded by a subsidence area. Conspicuous uplift of more than $10 \mathrm{~mm}$ was observed in an area 50 to $80 \mathrm{~m}$ long in the E-W direction and 25 to $40 \mathrm{~m}$ long in the N-S direction. In this conspicuous uplift area, it appears that two elliptical uplift areas were superimposed. The eastern elliptical uplift area corresponds to the conspicuous uplift area observed by Onishi et al. (2009), and its maximum uplift reached about $19 \mathrm{~mm}$, which is approximately $1 / 20$ of the uplift amount observed by Onishi et al. (2009). The western elliptical uplift has not been observed in the past. However, it had a maximum uplift that reached approximately $26 \mathrm{~mm}$ during the half-year observation period in 2012. In contrast, subsidence areas were observed in and around the uplift area mentioned above. The subsidence in these areas

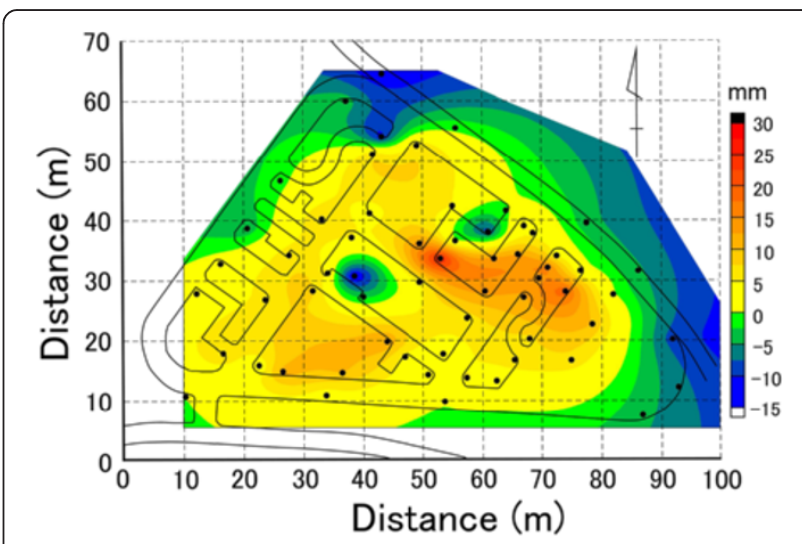

Figure 3 Vertical movement during June to December 2012. Displacements are in millimeters, and the contour interval is $2.5 \mathrm{~mm}$. Point $\mathrm{AO}$ is assumed to be fixed. 
reached 8 and $14 \mathrm{~mm}$, and such trends had not been observed in the past. The subsidence area that reached $14 \mathrm{~mm}$ corresponds to mud vent B (Figure 2). Near the active mud vent $C$ (Figure 2), uplift was observed instead of subsidence.

Figure 4 shows the vertical movements per month at each benchmark during the 6-month period. The vertical movements given by observations in October and July were divided by three to reduce the effects of the missing data due to bad weather in August and September, and then these values were averaged for each month (Figure 4). Figure 5A,B,C,D shows map views of the vertical movements per month. From these figures, it is evident that uplift and subsidence at the Murono mud volcano surface are recurrent events, and the range of vertical movements was found to be $0.5 \pm 6 \mathrm{~mm} / \mathrm{month}$ (Figure 4). Since the standard deviations of our leveling were smaller than $2 \mathrm{~mm}$ throughout the observation period, Figures 4 and 5 indicate significant vertical movements.

\section{Bouguer gravity anomaly}

Figure 6 shows the Bouguer gravity anomaly map. These anomalies were negative and were harmonized with the regional Bouguer gravity anomaly (e.g., Komazawa 2004). Such values indicate the existence of a low-density layer in and around this area. The values were lower in the center, and the maximum difference of the gravity anomaly reached approximately $0.3 \mathrm{mGal}$. This gravity low resembled a rotated 'L' and was near the area of conspicuous vertical movement shown in Figure 3.

\section{Discussion}

Onishi et al. (2009) performed the surface wave method that estimates distributions of shear-wave velocity by surface wave inversion (e.g., Park et al. 1999; O'Neill et al. 2006), and they observed low-velocity layers of less than $100 \mathrm{~m} / \mathrm{s}$ at depths of 1 to $5 \mathrm{~m}$ and at depths of more than $13 \mathrm{~m}$. It has been confirmed by excavation using a hand auger that the shallower low-velocity layer consists of a soft clay layer with low amounts of gravel. Onishi et al. (2009) suggested that the soft clay layer had been formed by erupted fluid mud, since it is widely distributed in this area. Yokota et al. (2008) conducted ground-penetrating radar (GPR) surveys in this area and detected conspicuous signal decline areas at high frequencies. The signal decline areas correspond to the conspicuous vertical movement areas observed in this study.

In observations of the deep structure, areas of low resistivity and circular low resistivity from a depth of $700 \mathrm{~m}$ to the surface have been measured by the controlledsource audio-frequency magneto-telluric (CSAMT) method, which implies that there is a mud chamber at a depth of $100 \mathrm{~m}$ (Suzuki et al. 2009). In addition, Shinya and Tanaka (2009) have conducted chemical analysis $\left(\delta^{18} \mathrm{O}\right.$ and $\delta \mathrm{D}$ values) of the erupted fluid mud, and they showed that this fluid mud has moved upward from a depth of 3.5 to $4 \mathrm{~km}$.

From the presence of shallow and deep structures and several small vents spouting gas and/or fluid mud in this area, it is likely that the gravity low shown in Figure 6 was caused by a low-density soft clay layer with high water content. It may be that effects due to low-density deep structures are included in these Bouguer gravity anomalies. However, since the wavelengths and amplitudes of the Bouguer gravity anomalies were very short and small, we believe that the gravity low is an anomaly caused by the very shallow low-density soft clay layer (1- to $5-\mathrm{m}$ depth or deeper than $13 \mathrm{~m}$ ) observed by Onishi et al. (2009). Although the scales of the mud volcanoes differ, similar gravity lows have been observed in the Lusi mud volcano in Indonesia (e.g., Istadi et al. 2009).

Since there were no earthquakes in the vicinity of the study area, and during the 6 months of our surveys we did not observe the conspicuous vertical movement reaching several tens of centimeters reported in previous studies, we think that the present Murono mud volcano is currently in a quiescence period. Thus, we conclude that the observed vertical movements were caused by activities of the mud volcano during the quiescence period.

Mud volcanoes with periodic activity change their vent locations and activities gradually, even in quiescence phases (e.g., Deville and Guerlais 2009). Although it is unknown whether activities of the Murono mud volcano are

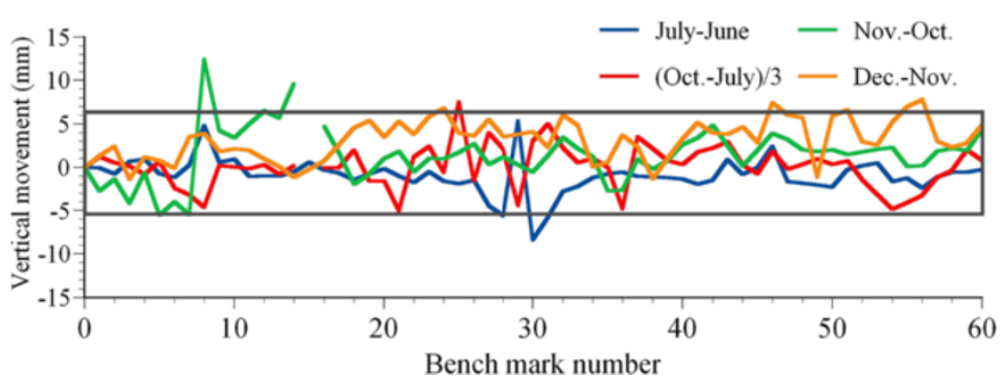

Figure 4 Vertical movements per month at each benchmark during June to December 2012. 

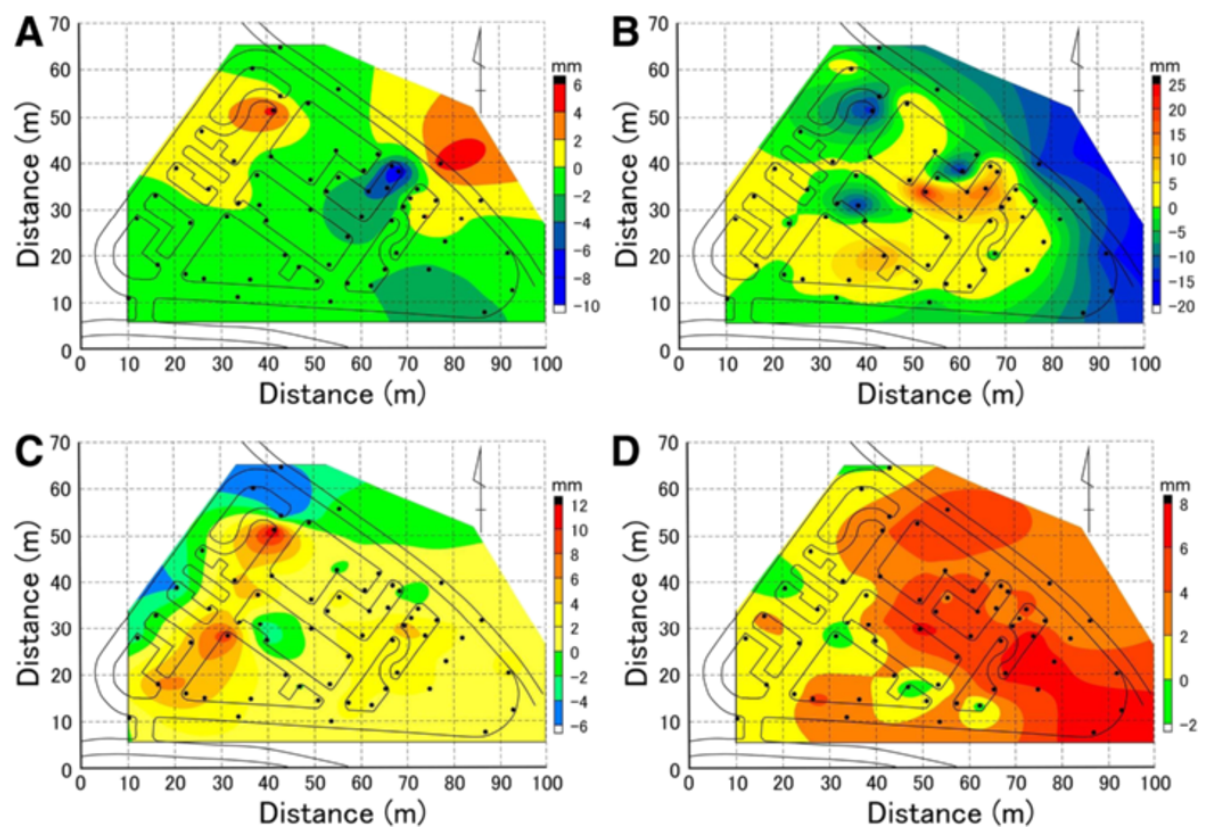

Figure 5 Vertical movements per month. Displacements are in millimeters. Point A0 is assumed to be fixed (Figure 2). (A) Vertical movement during June to July 2012. The contour interval is $2 \mathrm{~mm}$. (B) Vertical movement during July to October 2012. The contour interval is $2.5 \mathrm{~mm}$. (C) Vertical movement during October to November 2012. The contour interval is $2 \mathrm{~mm}$. (D) Vertical movement during November to December 2012. The contour interval is $2 \mathrm{~mm}$.

periodic, the locations and activities of vents in our study area have often changed in the same manner as shown by Deville and Guerlais (2009). These activity changes were also detected in the vertical movements per month, as shown in Figure 4. Notably, most benchmarks showed repeat uplift and subsidence each month. We think that these phenomena may be caused by a change of overpressure acting on the shallow soft clay layer at 1- to 5-m depth and/or deeper than $13 \mathrm{~m}$.

Hayashi et al. (2009) reported that the temperature change of the fluid mud under vent $\mathrm{C}$ (Figure 2) is unrelated to atmospheric temperature changes and that periodic

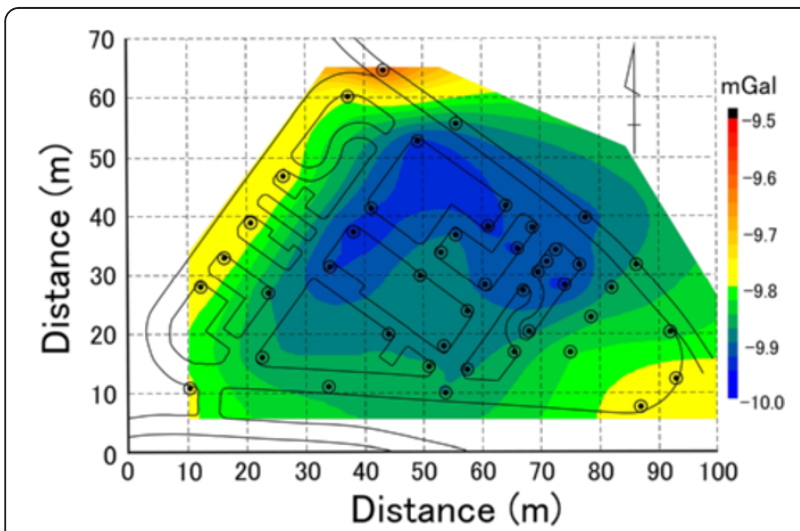

Figure 6 Bouguer gravity anomaly map. Contour interval is 25 $\mu \mathrm{Gal}$. The Bouguer density is assumed to be $2,400 \mathrm{~kg} / \mathrm{m}^{3}$. temperature changes of a few days to several weeks were also observed. From these observations, Hayashi et al. (2009) suggested that the temperature change may be caused by a change of flux and path of subsurface fluid flow. Since the temperature change of fluid mud reflects water flow, as shown by Deville and Guerlais (2009), and although there are cases where the temperature changes are not seen (e.g., Rudolph and Manga 2010), it is suspected that fluid mud flow can occur even during a quiescence period. Therefore, we suggest that overpressure due to fluid mud flow acts on the shallow soft clay layer and that its change deforms the surface. Since low-resistivity areas imply that fluid mud exists at depths in this area, as shown in Suzuki et al. (2009), we will need to extend the observation area in order to detect the signal caused by whole fluid flow.

\section{Conclusion}

We observed uplift and subsidence reaching $26 \mathrm{~mm}$ and $-14 \mathrm{~mm}$ in the Murono mud volcano located in the Niigata Prefecture of Japan during June to December 2012 by precise leveling measurements. The uplift was observed in two areas, one of which corresponds to the uplift area observed by past GPS surveys. The monthly vertical movements we observed indicate that uplift and/or subsidence areas do not always continue to experience these phenomena. Since no earthquakes occurred in the vicinity of the study area, and no conspicuous movement reaching 
several tens of centimeters (as reported in the past) was observed during the 6 months of our surveys, it is likely that the vertical movement observed by our leveling was caused by activities of the Murono mud volcano in its quiescence phase.

Bouguer gravity anomalies obtained in this area by past geophysical prospecting indicate the existence of a lowdensity layer such as soft clay with high water content.

Since the vertical movements observed in the Murono volcano have changed in a relatively short period of time and most of the benchmarks experienced recurrent uplift and subsidence, we suggest that changes in overpressure due to fluid mud flow deformed the surface and, furthermore, that these changes occurred in shallow layers.

\section{Competing interests}

The authors declare that they have no competing interests.

\section{Authors' contributions \\ SK planned this study and acquired data. He also confirmed the analyzed data and drafted this manuscript. KS acquired the leveling data and analyzed the datasets. He also wrote a part of this manuscript. MK acquired the gravity data and analyzed the datasets. She also wrote a part of this manuscript. TU acquired the leveling data. YF acquired the data and discussed the results we observed. All authors read and approved the final manuscript.}

\section{Authors' information}

SK is an associate professor of the University of Toyama. KS and MK were students of the University of Toyama at the time this research was conducted. TU is graduate school student. YF is a professor of Kyoto University.

\section{Acknowledgements}

We are grateful to Waseda University, which allowed us access to the Murono car test track. We are most grateful to Michael Manga and an anonymous reviewer for their constructive reviews and comments on the manuscript and to Shin'ichi Miyazaki for his editorial advice and cooperation. This study was partially supported by the discretionary budget of the President of the University of Toyama.

\section{Author details}

${ }^{1}$ Graduate School of Science and Engineering for Research (Science), University of Toyama, 3910 Gofuku, Toyama 930-8555, Japan. ${ }^{2}$ Department of Earth Science, Faculty of Science, University of Toyama, 3910 Gofuku, Toyama 930-8555, Japan. ${ }^{3}$ Department of Geophysics, Graduate School of Science, Kyoto University, Kitashirakawa Oiwake-cho, Sakyo-ku, Kyoto 606-8502, Japan.

Received: 19 September 2013 Accepted: 25 March 2014

Published: 22 April 2014

\section{References}

Banerjee B, Gupta SPD (1977) Gravitational attraction of a rectangular parallelepiped. Geophysics 42:1053-1055

Bonford G (2012) Geodesy. Hardpress, Miami

Bonini M (2007) Interrelations of mud volcanism, fluid venting, and thrustanticline folding: examples from the external northern Apennines (Emilia-Romagna, Italy). Jour Geophys Res 112, B08413, doi:10.1029/ 2006JB004859

Bonini M (2012) Mud volcanoes: indicators of stress orientation and tectonic controls. Earth-Sci Rev 115:121-152, doi:10.1016/j.earscirev.2012.09.002

Bonini M, Mazzarini F (2010) Mud volcanoes as potential indicators of regional stress and pressurized layer depth. Tectonophysics 494:32-47, doi:10.1016/ jtecto.2010.08.006

Chigira M, Tanaka K (1997) Structural features and the history of mud volcanoes in southern Hokkaido, northern Japan. Jour Geol Soc Japan 103:781-791
Davies RJ, Brumm M, Manga M, Rubiandini R, Swarbrick R, Tingay M (2008) The East Java mud volcano (2006 to present): an earthquake or drilling trigger? Earth Planet Sci Lett 272:627-638, doi:10.1016/j.epsl.2008.05.029

Deville E, Guerlais SH (2009) Cyclic activity of mud volcanoes: evidences from Trinidad (SE Caribbean). Mar Petrol Geol 26:1681-1691, doi:10.1016/ j.marpetgeo.2009.03.002

Dimitrov LI (2003) Mud volcanoes - a significant source of atmospheric methane. Geo-Mar Lett 23:155-161, doi:10.1007/s00367-003-0140-3

Etiope G, Milkov AV (2004) A new estimate of global methane flux from onshore and shallow submarine mud volcanoes to the atmosphere. Environ Geol 46:997-1002, doi:10.1007/s00254-004-1085-1

Etiope G, Lassey KR, Klusman RW, Boschi E (2008) Reappraisal of the fossil methane budget and related emission from geologic sources. Geophys Res Lett 35, L09307, doi:10.1029/2008GL033623

Etiope G, Nakada R, Tanaka K, Yoshida N (2011) Gas seepage from Tokamachi mud volcanoes, onshore Niigata Basin (Japan): origin, post-genetic alterations and $\mathrm{CH}_{4}-\mathrm{CO}_{2}$ fluxes. Appl Geochem 26:348-359, doi:10.1016/ j.apgeochem.2010.12.008

Feyzullayev AA, Lerche I (2009) Occurrence and nature of overpressure in the sedimentary section of the South Caspian Basin, Azerbaijan. Energy Explor Exploit 27:345-366, doi:10.1260/0144-5987.27.5.345

Fowler SR, Mildenhall J, Zalova S, Riley G, Elsley G, Desplanques A, Guliyev F (2000) Mud volcanoes and structural development on Shah Deniz. Jour Petrol Sci Eng 28:189-206

Hayashi T, Tokunaga T, Mogi K (2009) Subsurface temperature monitoring to evaluate the activity of a mud volcano: a case study in Matsudai, Niigata. Jour Geog 118:533-542 (in Japanese with English abstract)

Hofmann-Wellenhof B, Moritz H (2006) Physical geodesy, 2nd edn. Springer, Berlin

Imanishi K, Kuwahara Y (2009) Stress field in the source region after the $2007 \mathrm{MW}$ 6.6 Niigataken Chuetsu-oki earthquake deduced from aftershock focal mechanisms: implication for a pre-mainshock stress field. Earth Planets Space 61:1053-1065

Istadi BP, Pramono GH, Sumintadireja P, Alam S (2009) Modeling study of growth and potential geohazard for LUSI mud volcano: East Java, Indonesia. Mar Petrol Geol 26:1724-1739, doi:10.1016/j.marpetgeo.2009.03.006

Komazawa M (2004) Gravity grid database of Japan, Gravity CD-ROM of Japan, ver. 2, Digital Geoscience Map P-2. Geol Surv Japan, Tsukuba (in Japanese with English abstract)

Manga M, Brumm M, Rudolph ML (2009) Earthquake triggering of mud volcanoes. Mar Petrol Geol 26:1785-1798, doi:10.1016/j.marpetgeo.2009.01.019

Mazzini A, Nermoen A, Krotkiewski M, Podladchikov Y, Planke S, Svensen H (2009) Strike-slip faulting as a trigger mechanism for overpressure release through piercement structures. Implications for the Lusi mud volcano, Indonesia. Mar Petrol Geol 26:1751-1765, doi:10.1016/j.marpetgeo.2009.03.001

Mellors R, Kilb D, Aliyev A, Gasanov A, Yetirmishli G (2007) Correlations between earthquakes and large mud volcano eruptions. Jour Geophys Res 112, B04304, doi:10.1029/2006JB004489

Morley CK (2007) Development of crestal normal faults associated with deepwater fold growth. Jour Struct Geol 29:1148-1163, doi:10.1016/ j.jsg.2007.03.016

Noda H (1962) The geology and paleontology of the environs of Matsunoyama, Niigata Prefecture, with reference to the so-called black shale. Sci Rep Tohoku Univ Ser 2(34):199-236

O'Neill A, Safani J, Matsuoka T (2006) Rapid shear wave velocity imaging with seismic landstreamers and surface wave inversion. Exp Geophys 37:292-306

Onishi K, Sanada Y, Yokota T, Tokunaga T, Mogi K, Safani J, O'Neill A (2009) Investigation of subsurface S-wave velocity structures beneath a mud volcano in the Matsudai-Murono district by surface wave method. Jour Geogr 118:390-407 (in Japanese with English abstract)

Panahi BM (2005) Mud volcanism, geodynamics and seismicity of Azerbaijan and the Caspian Sea region. In: Martinelli G, Panahi B (eds) Mud volcanoes, geodynamics and seismicity. Springer, Berlin

Park CB, Miller RD, Xia J (1999) Multichannel analysis of high frequency surface waves. Proc Sympo Env Prob 99:115-121

Rudolph ML, Manga M (2010) Mud volcano response to the 4 April $2010 \mathrm{El}$ Mayor-Cucapah earthquake. Jour Geophys Res 115, B12211, doi:10.1029/ 2010JB007737

Sagiya T, Miyazaki S, Tada T (2000) Continuous GPS array and present-day crustal deformation of Japan. Pure Appl Geophys 157:2303-2322 
Shinya T, Tanaka K (2009) Origin of materials erupting from mud volcano in Tokamachi city, Niigata Prefecture, central Japan. Jour Geogr 118:340-349 (in Japanese with English abstract)

Suzuki K, Tokuyasu S, Tanaka K (2009) Underground structure of mud volcanoes in Tokamachi city, Niigata Prefecture determined by electromagnetic exploration, and geographical and geological surveys. Jour Geogr 118:373-389 (in Japanese with English abstract)

Takeuchi K, Yoshikawa T, Kamai T (2000) Geology of the Matsunoyama onsen district with geological map at 1:50,000. Geol Surv Japan, Tsukuba (in Japanese with English abstract)

Yokota T, Onishi K, Sanada Y (2008) Geophysical explorations of shallow structure of mud volcano using a ground penetrating radar system in Matsudai, Tokamachi City, Niigata Japan. Chishitsu News 644:25-32 (in Japanese)

doi:10.1186/1880-5981-66-14

Cite this article as: Kusumoto et al: Vertical movement during the quiescent phase of the Murono mud volcano, Niigata, Japan. Earth, Planets and Space 2014 66:14

\section{Submit your manuscript to a SpringerOpen ${ }^{\circ}$ journal and benefit from:}

- Convenient online submission

- Rigorous peer review

- Immediate publication on acceptance

- Open access: articles freely available online

- High visibility within the field

- Retaining the copyright to your article 